\title{
De fontes a agentes jornalísticos: a crítica de uma metáfora morta
}

\section{Bruno Souza Leal}

Doutor; Universidade Federal de Minas Gerais

brunosleal@gmail.com

\section{Carlos Alberto Carvalho}

Doutor; Universidade Federal de Minas Gerais

carloscarvalho0209@gmail.com

\section{Resumo}

$\mathrm{O}$ artigo, a partir do mergulho em um vasto corpus de narrativas sobre homofobia e HIV/Aids em meios impressos e eletrônicos, discute os limites da noção usual de fontes jornalísticas, observando-as como agentes jornalísticos. O termo "fonte" é bastante recorrente nos processos jornalísticos e nos estudos acadêmicos, sendo quase sempre pouco problematizado. Na maioria das vezes, ou desenvolve-se um esforço classificatório das fontes ou elas surgem em abordagens que poderíamos identificar como "sob suspeita quanto aos seus reais propósitos". Quase sempre, as fontes jornalísticas parecem ter vida somente na relação imediata e mecânica com o universo da produção noticiosa. São poucos os trabalhos, porém, que observam que o termo é uma metáfora bastante cristalizada e que, por isso mesmo, talvez tenha perdido seu potencial heurístico de apreensão do fenômeno jornalístico.

\section{Palavras-chave}

Fontes. Agentes. Jornalismo. Homofobia. Narrativa.

\section{Introdução}

Entre 2008 e 2012 foram realizadas três pesquisas que, articuladas, buscaram apreender o modo como mídias noticiosas brasileiras lidavam com a homofobia, com as populações LGBT e a epidemia de HIV/Aids. A primeira da série, denominada Mídia e homofobia no Brasil, foi realizada em 2008, com apoio do Ministério da Saúde, e teve como universo pesquisado os jornais Folha de S. Paulo, O Globo e O Tempo, a revista Veja e os telejornais da TV Globo Jornal Nacional e MGTV - $2^{a}$ edição. A sequência, com pequenas variações quanto às 
mídias investigadas (saíram o jornal $O$ Tempo e o MGTV $2^{a}$ edição, com a entrada da revista Época e do Jornal Hoje), foi denominada Jornalismo e Homofobia no Brasil e realizada em 2009 e 2010, com apoio do CNPq e da Fapemig. Uma última pesquisa, denominada Jornalismo e atores sociais: análise de narrativas sobre homofobia e HIV/Aids nos jornais Estado de Minas, Folha de S. Paulo e O Globo nos anos de 2011 e 2012, foi realizada com apoios da Fapemig e da Pró-Reitoria de Pesquisa da UFMG e teve uma abrangência menor de mídias noticiosas escrutinadas. Compartilhando um mesmo referencial teórico (no qual se destacam, entre outros, BORILLO, 2001; ERIBON, 2008, FACCHINI, 2005) e procedimentos metodológicos, essas três pesquisas recolheram um conjunto de mais de 5 mil notícias, devidamente indexadas e armazenadas em um banco de dados digital. Um dos objetivos das três pesquisas foi observar quem surgia, na superfície noticiosa, como agente social relevante no diz que respeito ao combate ou à promoção da homofobia, na busca do reconhecimento, conquista ou rechaço dos direitos das populações LGBT e vinculadas a ações, de distintas qualidades, relacionadas à epidemia HIV/Aids.

Num momento inicial, uma das intenções era identificar quem seria o protagonista ou o ator social mais relevante do acontecimento noticiado. Assim, a exemplo de outros trabalhos (como os de TOMÉ; LOPES, 2012), buscava-se reconhecer quem, na superfície narrativa da notícia, era apresentada como sua fonte principal e, com isso, pretendia-se observar tanto "quem fala do quê" nas matérias quanto os modos de apresentação dessas personagens e os possíveis silenciamentos. No entanto, essa perspectiva inicial foi confrontada com pelo menos três aspectos importantes:

a) nem sempre o promotor do acontecimento era "quem falava" na notícia, que, então, apresentava um "mundo possível" (LEAL; JACOME, 2011; ECO, 2002; RYAN, 2001; FARRÉ, 2006, entre outros) construído no processo de produção jornalística a partir de uma interpretação específica de um (ou mais) evento(s);

b) a dissociação entre os promotores dos eventos e as personagens presentes nas notícias sugeria - e em alguns momentos deixava ver de modo bastante evidente - que algumas falas e entrevistas eram claramente "convocadas" pelos jornalistas em função do enquadramento predefinido pela mídia informativa e das necessidades narrativas da história que se contava;

c) foi possível identificar que havia uma zona "cinzenta", impossível de ser apreendida com precisão na leitura das matérias, que implicava exatamente as definições e os porquês dessas escolhas e seleções, desses enquadramentos, desses 
modos de narrar etc. Na leitura de uma dada notícia ou mesmo no seu cotejamento com outras, sobre um mesmo acontecimento ou sobre eventos semelhantes, foi possível no máximo conjecturar o impacto do posicionamento políticoideológico de cada mídia informativa, o papel das chamadas fontes oficiais ou dos próprios valores que regem a atividade jornalística, tal como observam, entre outros, Barbie Zelizer (2004), Andrew Calcutt e Philip Hammond (2011) e diferentes artigos reunidos por Leal, Antunes e Vaz (2014).

Diante desse quadro, este artigo, por um lado, reflete sobre a adoção do uso do termo "agente", em detrimento de "fonte", para designar aqueles que conformam e/ou se apresentam na notícia. Todos esses agentes são, de alguma forma, jornalísticos, pois atuam, cada um a seu modo, no processo jornalístico. Certamente têm força e peso distinto dos jornalistas e das organizações empresariais midiáticas, mas não deixam de merecer o adjetivo "jornalístico" por causa disso. Por outro lado, a adoção do termo "agente" não busca simplificar ou desconsiderar as clivagens indicadas acima. Ao contrário: reconhecer o que se chamou de "fonte" como "agente" é um esforço de alcançar diferentes modos de atuação e inserção no mundo das notícias. Nesse sentido, a reflexão aqui proposta tem uma dupla referência: tanto as pesquisas realizadas sobre a cobertura jornalística sobre a homofobia e HIV/Aids quanto à percepção de que um vasto conjunto de pesquisas e estudos acerca do jornalismo já indicam, direta ou indiretamente, a exaustão da imagem da "fonte" jornalística. Assim, parte-se inicialmente da pergunta "quem fala o quê?" nas notícias de modo a retomar criticamente essa imagem da fonte, que é então entendida como metáfora morta, cujo potencial heurístico encontra-se cada vez mais esvaziado. A seguir, apresenta-se inicialmente uma parte dos resultados das pesquisas, aquelas em torno dos agentes sociais que puderam ser identificados como protagonistas das notícias sobre homofobia, populações LGBT e a epidemia HIV/Aids. Como consequência desse percurso, avalia-se, mesmo brevemente, a expressão "agente" como possivelmente mais pertinente para os processos jornalísticos atuais. 


\title{
2 Quem fala o quê? A fonte como metáfora morta
}

A questão "quem fala o quê" na notícia, aparentemente simples, revela-se como algo bem mais complexo. Não se trata apenas, como se poderia pensar, de identificar, no texto noticioso, a presença e/ou papel de uma determinada fonte. No processo noticioso, como observa didaticamente Jurandira Fonseca (2014), a pergunta abre-se a várias outras:

\begin{abstract}
Mas afinal, quem fala no jornalismo? A pergunta pode parecer óbvia, mas significativamente não é. 0 discurso ali presente pertence ao jornalista que relata os fatos? Aos veículos onde as notícias são divulgadas? Aos personagens envolvidos? Às pessoas que participaram dos acontecimentos ou a eles assistiram? Ou aos setores interessados nos acontecimentos? E mais, quem ganha voz na imprensa? Quem é acionado e chamado a falar e legitimado como porta-voz de informações relevantes? A quem é dada a oportunidade de se manifestar na privilegiada arena midiática? Quem define e quem diz a suposta "verdade" dos fatos? (FONSECA, 2014, p.9192 , grifos nossos).
\end{abstract}

Essas perguntas encontram um exemplo claro na cobertura das paradas de orgulho LGBT, comumente chamadas de "Paradas do Orgulho Gay". No período das pesquisas, as Paradas foram, em sua maioria, organizadas por ONGs vinculadas à luta pelo reconhecimento dos direitos dessas populações. No entanto, essas mesmas ONGs praticamente não surgiam, na superfície da notícia, como agentes desse acontecimento público, perdendo espaço para as pessoas comuns, as celebridades, a polícia, os especialistas e mesmo órgãos do Executivo. A presença desses outros agentes sociais, alguns deles inclusive indiretamente ligados aos eventos, explicitou o hiato existente entre os acontecimentos sociais, os processos de apuração e reportagem e a construção narrativa das notícias e demais textos jornalísticos. Menos que em uma relação linear, a articulação acontecimento/reportagem/notícia se dá imersa em um amplo e difuso conjunto de mediações, como diferentes pesquisas recentes têm apontado (BENETTI; FONSECA, 2010; LEAL et al., 2011; BERGER et al., 2013; SILVA et al., 2014; FRANÇA; OLIVEIRA, 2012, entre outros). A produção da notícia envolve um campo de disputas desigual, no qual diferentes agentes sociais (que também integram a "comunidade interpretativa" do jornalismo, como observam LEAL; JÁCOME, 2013) concorrem entre si por espaços, enquadramentos e falas, podendo se impor ou não, serem "convocados" ou não, como fontes legítimas e/ou como agentes/personagens nas narrativas informativas.

0 incômodo com a noção de fonte e a percepção da complexa relação entre os agentes noticiosos não é necessariamente algo novo nos estudos sobre o jornalismo. Um exemplo é a provocação de Érik Neveu: 
A metáfora da fonte de informação é cheia de mal-entendidos. Ir à fonte sugere um comportamento ativo para se abastecer de um produto (água ou informação) naturalmente disponível. Esse jogo de conotações combina com as imagens do jornalista curioso e investigador. Ele induz a erro, não porque os jornalistas sejam desprovidos de espírito de iniciativa e habilidades para acessar a informação escondida, mas porque as fontes são hoje fundamentalmente ativas. Se uma metáfora aquática pode fazer sentido, é a de jornalistas submersos num dilúvio de informações oferecidas pelas fontes. (NEVEU, 2006, p. 94-95).

Há pelo menos duas vantagens nas provocações de Neveu (2006). A primeira está em ressaltar a natureza metafórica do termo fonte e, portanto, a partir daí fica o alerta para não tomá-lo como um conceito. A segunda vantagem está no fato de que Neveu (2006) destaca o caráter proativo das fontes, ao contrário de abordagens nas quais elas são meras entidades sujeitas às manipulações de jornalistas.

Há de se destacar, no entanto, que de uma condição de metáfora o termo "fonte" tem sido adotado como se fosse um conceito de grande poder heurístico. Nessa condição, encontramos larga aplicação da noção de fontes a partir de critérios classificatórios, notadamente aqueles mais simplistas, que as distinguem entre oficiais (para alguns, institucionais), oficiosas, independentes (LAGE, 2001; PENA, 2005; BORRAT, 2006; REBELO, 2000), agências de notícias, o repórter, o arquivo das mídias, outras mídias noticiosas, correspondentes nacionais e internacionais (CRATO, 1992), dentre outras variáveis limitadas à unilateralidade da circularidade referida. Em uma série de estudos, por sua vez, as noções de definidores primários e definidores secundários têm sido utilizadas, a partir da proposição de Stuart Hall (2003) - de que os primeiros são fontes de destaque em função de sua representatividade e status institucional, enquanto os segundos caracterizam-se por certa marginalidade e pouco peso social (NEVEU, 2006) - mesmo se considerando as críticas já desenvolvidas em torno dessa percepção (como as coligidas por ZELIZER, 2004).

Simultaneamente ou não aos sistemas classificatórios, outra preocupação relativa às fontes está em questionamentos sobre onde se situa o poder das mídias jornalísticas, tal como nas reflexões de Michael Schudson, que lembre que "fontes: elas são o grande segredo do poder da imprensa. Grande parte desse poder é exercido não pelas próprias instituições de notícias, mas pelas fontes que as alimentam com informações." (SCHUDSON, 2003, p. 134). Da proposição de Schudson (2003) é importante reter a ideia de que, permeando as relações entre fontes-jornalistas-notícia, estão interesses de diversificados sistemas de poder. No entanto, o autor não escapa de todo das visões que tendem a situar o poder da imprensa, ainda que negociado, como um tipo de exercício de influência desequilibrado favo- 
ravelmente às mídias e seus operadores, mesmo que chamando atenção para o papel fortemente desempenhado pelas fontes na determinação dos matizes dos acontecimentos narrados. Nesse sentido, nos estudos sobre o jornalismo, de diferentes vertentes e perspectivas, encontra-se um vasto conjunto de reflexões críticas - tão vasto que é impossível de ser compilado aqui - que direta ou indiretamente contribuem para a revisão do papel das "fontes" nos processos jornalísticos. Esses estudos observam desde o impacto de novos agentes sociais e transformações tecnológicas (sejam consumidores ou diferentes figuras profissionais) na definição das notícias, no mercado de trabalho ou mesmo na configuração de uma possível crise contemporânea do jornalismo, questões éticas-deontológicas, novas e mais adequadas taxonomias, até a revisão de conceitos como gatekeeper e gatewatcher, entre outros (GITTLIN, 2013; NÉVEU, 2010; FÍGARO, 2013; BURNS, 2013; BRAGA et al., 2014; ZELIZER, 2008; SHOEMAKER; VOSS, 2011; MORETZSOHN, 2012, entre vários outros)

É significativo notar que o uso do termo "fonte", nas mais diversas correntes dos estudos jornalísticos, vem sempre acompanhado de correções e esclarecimentos. Praticamente em todas as vertentes de tratamento classificatório das fontes, por exemplo, estão presentes preocupações com as questões éticas, notadamente aquelas que dizem respeito diretamente à relação fontes-jornalistas, com indicações de que é a partir da preservação de princípios deontológicos que se garantiria a narrativa fiel dos acontecimentos, segundo a ilusão de que "a verdade" sobre o narrado seria preservada (CORNU, 1994). Questões como o uso de off (declarações obtidas de fontes supostamente confiáveis mantidas em sigilo), a não aceitação de brindes de fontes por jornalistas, a verificação da informação com mais de uma fonte e a manutenção de relações de mútua confiança também aparecem no elenco das questões de ordem ética e deontológica.

Mas é a desconfiança sobre os reais interesses das fontes jornalísticas, particularmente daquelas identificadas com o universo político-partidário e governamental, o que mais sobressai da leitura de uma vasta gama de autores que se debruçam sobre os interesses não necessariamente explicitados e/ou legítimos das fontes. Das críticas às ações de lobbies, assessorias de imprensa, serviços de relações públicas, passando pelo papel dos spin doctors pessoas especialmente treinadas para falarem bem de governos ou outras pessoas e instituições - tal como Michael Schudson (2003, p. 147) identifica em especial no contexto de disputas eleitorais nos Estados Unidos, é grande a lista que engrossa a desconfiança quanto à sinceridade das fontes e os eventuais prejuízos à "verdade" do que é narrado a partir das informações por elas passadas a jornalistas. A relação, claro, não se limita aos contatos iso- 
lados de jornalistas com suas fontes, mas também interesses eventualmente não deixados claros pelas empresas jornalísticas, tal como indica Daniel Cornu:

A relação do jornalista com as suas fontes não depende, portanto, unicamente das influências directas. É fortemente determinada pelas relações mantidas pela empresa de imprensa com o seu ambiente. É-o de forma directa e caracterizada relativamente a todas as pessoas ou instituições que representam um poder, político mas também económico ou cultural. Quando a dependência é demasiado forte, o jornalista deixa de interrogar previamente sobre os critérios de seleção. A questão não é assim se ele difunde ou não a informação, mas qual o tratamento que lhe reserva: o tamanho da notícia, o seu apoio com uma ilustração (ou com imagens em televisão), a sua colocação no alinhamento do jornal ou da emissão, a sua paginação, os seus eventuais prolongamentos. (CORNU, 1994, p. 272-273).

Embora todos os interesses apontados por Cornu (1994), e certamente mais alguns, estejam em jogo na construção narrativa de acontecimentos diversos - o que denominamos de disputas de sentido - o cuidado é não tomar tais disputas como se elas envolvessem unilateralmente a vontade de pessoas e/ou instituições. Em outras palavras, as disputas de sentido têm a ver com visões sociais de mundo que colocam em cena atores extremamente diversificados e é preciso não atribuir de forma mecânica e maniqueísta o poder a apenas uma das partes envolvidas. Por outro lado, não é recente a percepção do gesto interessado e eticamente comprometido do jornalista em relação às "fontes" que elege e que encontra, por exemplo, na obra de Janet Malcolm (2011), "O jornalista e o assassino", um dos seus marcos mais instigantes.

Dessa forma, a imagem da "fonte" - que, como Néveu (2006) chama atenção, remete ao ideal de pureza natural - é necessariamente contaminada (e corrigida, de vários modos) por diferentes percepções de como o processo jornalístico efetivamente se dá. Nesse sentido, entender o termo "fonte" como metáfora é fundamental. As metáforas são recursos profícuos para inovações semânticas, para as possibilidades de arejamento e expansão dos modos de conhecimento, sejam eles vinculados ao senso comum ou à compreensão científica e filosófica. As metáforas, como imagens, permitem dar relevo a alguns aspectos de relações, situações, personagens e acontecimentos, ao mesmo tempo que invisibilizam outras dimensões e qualidades. As metáforas, como recurso interpretativo, são necessariamente "impertinentes", no sentido de que, não sendo "naturais" ou "orgânicas" aos seus referentes, tomálas literalmente significa retirar as potencialidades heurísticas que elas propiciam (RICOEUR, 2005, 2011). É essa a distinção que faz Paul Ricoeur $(2005,2011)$ entre metáforas vivas e mortas, ou seja, entre aquelas que mantêm sua impertinência, sua potencialidade heu- 
rística e as outras que, naturalizadas, desgastadas pelo uso acrítico, deixam de incomodar, de oferecer questões e problemas quando associadas a um dado fenômeno.

0 termo "fonte", usado sem maiores problematizações, certamente não permite ver que os processos de obtenção de informação, de definição de enquadramentos e modos de interpretação, de configuração narrativa da notícia e de sua apreensão envolvem dinâmicas complexas, em diferentes jogos de interesse, de poder e ação se fazem presentes. Sugerindo a ideia de uma informação a ser ofertada naturalmente e a ser simplesmente "recolhida" pelos jornalistas, o termo exige sempre ser corrigido e adequado para dar conta dessa gama de relações que apaga. Nesse sentido, é de se perguntar: se o termo necessita dessas correções, se se mostra claramente insuficiente, como se vê, qual a razão de mantê-lo?

\section{Diferentes protagonismos: no acontecimento, no enquadramento, na história}

Metodologicamente estruturadas numa combinação de análise de conteúdo e análise narrativa, as pesquisas não puderam alcançar com precisão as clivagens entre os agentes dos acontecimentos, os que se apresentavam no processo de produção jornalística e os que foram apresentados nas narrativas noticiosas, a não ser em casos excepcionais e explícitos como os das Paradas de Orgulho LGBT. O quadro abaixo apresenta, em termos gerais, os protagonistas identificados no conjunto de matérias recolhidas nas três pesquisas. Ressaltase que em cada notícia foi identificado um único agente principal:

Quadro 1- Agentes em coberturas jornalísticas sobre HIV/Aids e homofobia

\begin{tabular}{|c|c|c|c|c|c|c|c|c|}
\hline Executivo $^{1}$ & Legislativo & Judiciário & Celebridades & Igrejas & $\begin{array}{c}\text { Universidades/ } \\
\text { Centros de } \\
\text { Pesquisa/ } \\
\text { Pesquisadores/ } \\
\text { Médicos }\end{array}$ & $\begin{array}{c}\text { Movimentos } \\
\text { Sociais/ONG's }\end{array}$ & Anônimos & Empresas \\
\hline 582 & 202 & 170 & 2940 & 312 & 369 & 229 & 1039 & 163 \\
\hline
\end{tabular}

Fonte: Adaptação de Leal e Carvalho (2012) e pesquisa Jornalismo e atores sociais: análise de narrativas sobre homofobia e HIV/Aids nos jornais Estado de Minas, Folha de S. Paulo e O Globo nos anos de 2011 e 2012

Nesse quadro, chama atenção a presença relativamente pequena dos três poderes constitucionais nas matérias jornalísticas. Somadas, as notícias que tanto os mencionam como os têm como agentes dos acontecimentos narrados totalizam 954, menos de um terço daquelas que tratam de celebridades e menos até do que aquelas que narram as histórias das pessoas comuns (chamadas aqui de anônimos). Olhados separadamente, o Legislativo e

${ }^{1}$ Inclui Polícia 
o Judiciário ocupam, respectivamente, a antepenúltima e a penúltima posição entre os agentes sociais identificados. Cabe esclarecer que os poderes Legislativo e Judiciário que apareceram nas narrativas foram majoritariamente brasileiros. Já o Executivo, embora na maioria das vezes identificado com os governos federal, estaduais e municipais do país e suas forças policiais, também aparece a partir de governos estrangeiros e de organismos ligados à Organização das Nações Unidas, especialmente aqueles das áreas da saúde e dos Direitos Humanos.

Em princípio, o quadro acima parece contradizer o entendimento recorrente, em grande parte da bibliografia sobre o jornalismo, de que há uma dependência ou um privilégio das fontes oficiais na definição e na construção das notícias. 0 predomínio das celebridades e das pessoas comuns sugere que, pelo menos no que diz respeito à temática em tela, essa dependência não se dá. Há um outro entendimento possível, porém: o que distingue a produção da notícia da sua construção narrativa. Em outras palavras, não é exatamente porque há um conjunto de pessoas comuns apresentadas como protagonistas das notícias que elas não espelham uma visão fortemente oficial sobre o acontecimento narrado. Um exemplo claro foram matérias sobre o impacto da distribuição de medicamentos antirretrovirais na diminuição da infecção por HIV e na melhoria da qualidade de vida dos infectados. Essas matérias quase sempre foram motivadas por ações do Ministério da Saúde através de campanhas publicitárias (recorrentes no período do Carnaval) ou da divulgação de boletins epidemiológicos. Muitas dessas notícias tinham como protagonistas, como personagens principais, pessoas comuns, portadoras do HIV, que ilustravam, materializavam, humanizavam o dado impessoal divulgado pelo Ministério e referido, ao longo do texto, de modo secundário, complementar. Essas pessoas foram convocadas como detentoras de informação relevante para a narrativa em função de uma notícia definida, porém, a partir da relação com outro agente social.

Outro exemplo ocorreu em 2010, quando os jornais Estado de Minas, Folha de S. Paulo e $O$ Globo deram destaque ao principal dado então ressaltado: o crescimento do número de infecções pelo HIV por jovens homossexuais. A partir desses dados, algumas narrativas jornalísticas buscaram explicações para o fenômeno, uma clara indicação de que as definições de pautas pela ação do Executivo, naquela situação, extrapolaram os limites dos dados epidemiológicos apresentados motivando, por exemplo, notícias que exploraram aspectos comportamentais. Um exemplo está na narrativa "Essa molecada não viu a cara da Aids com tratamento, cresce comportamento de risco de jovens gays" (FREIRE, 2010, p. 10), pu- 
blicada pelo jornal $O$ Globo, cujo título dá uma boa ideia da influência dos dados do Ministério da Saúde na elaboração da pauta.

Muito significativas também são as diferenças qualitativas detectadas na caracterização dos três poderes constitucionais frente aos temas escolhidos. Com algumas exceções, o conjunto das matérias aponta para um quadro no qual o Poder Legislativo é o mais refratário a posições de reconhecimento da homofobia como grave problema social, posição diametralmente oposta àquela verificada relativamente ao Poder Judiciário. O Poder Executivo aparece como um agente ambíguo entre as duas posições, ora adotando ações de combate à homofobia, ora sucumbindo a pressões conservadoras em suas políticas referentes a ela. Segundo as notícias coletadas, as questões relativas ao HIV/Aids, com ou sem interconexão com a homofobia, têm no Executivo seu principal agente, e nesse caso, as notícias se mostram quase sempre favoráveis a políticas públicas de controle do avanço do HIV, de distribuição de medicamentos e, ocasionalmente, ao combate à homofobia, quando esta interfere na dinâmica do combate ao HIV.

Duas narrativas ilustram posicionamentos antagônicos dos poderes Legislativo e Judiciário. Em 28 de agosto de 2010, a Folha de S. Paulo traz, no caderno Cotidiano, na página C1, notícias cujos títulos já indicam o contraponto: "STJ garante direito de adoção a casal gay" e "Câmara tem projetos que vetam adoção por casais do mesmo sexo". Sobre o direito de adoção, a matéria informa que "é a primeira vez no Brasil que um tribunal superior reconhece esse direito; caso também será analisado pelo Supremo Tribunal Federal" e que a decisão foi tomada para atender ao interesse do menor, que é de ser adotado, segundo explicação do ministro João Otávio de Noronha, da 4⿳亠丷厂 Turma do STJ (SELIGMAN, 2010, p. C1). Sobre os projetos em discussão na Câmara Federal, a notícia informa que, se aprovados, um altera o Estatuto da Criança e do Adolescente, e outro, o Código Civil, destacando que ambos mantêm os mesmos argumentos, que giram em torno de supostos transtornos para as crianças adotadas. Nas palavras do deputado Zequinha Marinho, que segue o exemplo de legislação ucraniana, "uma criança cujos pais adotivos mantenham relacionamento homoafetivo terá grandes dificuldades em explicar a colegas de escola porque tem dois pais, sem nenhuma mãe, ou duas mães, sem nenhum pai" (CÂMARA, 2010, p. C1).

Ainda que nos valendo de poucos exemplos, eles nos dizem que, no caso do Poder Legislativo, as notícias coletadas sugerem que ele adota posições contrárias ao combate à homofobia, pois, além disso, vem protelando a aprovação de lei que tipifique como crime específico os praticados por motivos homofóbicos, sobretudo por posição de bancadas conser- 
vadoras alinhadas a grupos evangélicos e católicos. Tais informações foram recorrentes em nosso corpus, ao mesmo tempo em que o Poder Judiciário poucas vezes apareceu como agente contrário a posições de combate à homofobia e suas consequências, situação cuja explicação - referendada pelas narrativas jornalísticas - estaria no fato de não sofrerem as mesmas pressões eleitorais importantes para os representantes do Legislativo.

Sobre o Poder Executivo, um exemplo de suas ações está na nota publicada na Veja, edição de 5 de março de 2008, sob o título "Mudança de sexo no SUS", que informa decisão do então ministro da Saúde, José Gomes Temporão, de determinar ao SUS que faça gratuitamente cirurgias de mudança de sexo, assim como define que médicos deverão tratar os pacientes pelo nome que eles preferirem, independente daquele que constar na carteira de identidade. "Com isso, homens poderão ser chamados por nomes femininos, e vice-versa" (MUDANÇA, 2008, p. 40). Acontecimentos relativos à área da saúde predominam nas narrativas que têm o Poder Executivo como agente, variando de políticas públicas como as noticiadas por Veja a ações voltadas para o combate à epidemia do HIV/Aids. Entre elas, a distribuição de medicamentos para HIV/Aids, a redução de impostos para estes mesmos medicamentos e, anualmente, próximo ao Dia Mundial de Combate à Aids (1ํ de dezembro), a divulgação de dados epidemiológicos sobre a síndrome que, algumas vezes, rendem narrativas que vão além daquelas derivadas diretamente dos números apresentados pelo Ministério da Saúde.

A recorrência desses enquadramentos surge, então, como um enigma: qual a sua origem, a sua fonte? Eles advêm de uma percepção correta e justa sobre a ação dos três poderes? Se sim, como considerar as contradições e tensões internas presentes em cada um deles? A resposta seria vinculada a uma espécie de "visada cultural" dominante sobre cada um desses poderes, como uma espécie de preconceito historicamente enraizado na vida social ou na "cultura jornalística" brasileira, pelo menos? Ou da ação - estratégica, necessariamente - das pessoas ouvidas na produção de cada matéria? Parece-nos claro, nesse sentido, que não há uma explicação única, fácil e simples. De qualquer modo, essa rápida revisão dos resultados das pesquisas exige que se avalie com mais cuidado o que se entende como fonte jornalística. 


\section{Das fontes aos agentes}

Ao invés de fontes, que integrariam uma posição particular na linha reta da produção do acontecimento em notícia, as pesquisas se depararam com uma rede complexa de interações e agenciamentos, que, vistas a partir das narrativas noticiosas, mantêm uma zona de sombra e fora do alcance. Essa rede de interações, nada linear, é integrada por agentes, num triplo sentido: aqueles que atuavam como promotores dos acontecimentos, muitas vezes com vistas à sua noticiabilidade - como é caso das paradas, construídas, entre outros intuitos, como um grande evento público a ser noticiado, e também de uma vasta gama de outros eventos sociais -; aqueles a partir dos quais os jornalistas e as mídias informativas estabeleciam seu entendimento; e os que se apresentavam, na tessitura narrativa, como seus protagonistas ou como figuras de autoridade sobre o que é narrado.

A partir do exposto, sugere-se que agentes são pessoas e/ou instituições presentes nos processos e narrativas jornalísticas sobre acontecimentos diversos a partir da dinâmica de disputas de sentido em torno do que (e como) é narrado, propondo pontos de vista que revelam visões sociais de mundo diversas. Como atuam os agentes, de uma perspectiva analítica, requererá que a cada pesquisa sejam construídas estratégias metodológicas capazes de dar conta das especificidades de atuação em função dos acontecimentos sob escrutínio. No entanto, parece-nos necessário considerar as seguintes variáveis:

a) o termo "agente" se aplica a diferentes operadores, que atuam de modo distinto na cadeia noticiosa, como por exemplo na promoção do evento a ser noticiado; na produção da notícia; na superfície narrativa da história construída e posta em circulação pelas mídias informativas; no entendimento dos sentidos e implicações dessa história;

b) não há na apreensão dos modos de atuação desses agentes qualquer linearidade ou simplificação possível. Mesmo se inscrevendo em um momento ou outro, um agente tem uma atuação complexa, desempenhando frequentemente mais de um papel. Assim, por exemplo, as pessoas comuns chamadas para ilustrar matérias sobre a epidemia HIV/Aids não são simples "objetos", mas muitas vezes agentes interessados, conhecedores e familiarizados, ao menos em parte, com as notícias, e que se deixaram capturar pelo processo noticioso a partir de distintas motivações; 
c) agentes possuem papel ativo na definição dos sentidos atribuídos aos acontecimentos narrados, mesmo quando procurados por jornalistas, o que em tese os colocaria sob a condição de meros informantes. Mesmo quando na defensiva, respondendo por alguma acusação, por exemplo, os agentes não perdem sua capacidade de matizar o que é noticiado;

d) os agentes têm poderes distintos, inscrevendo-se no processo noticioso de modo específico, ao sabor das correlações de força que mantêm e que, por sua vez, podem variar no ritmo das interações desenvolvidas;

e) os pontos de vista expressos pelos agentes devem ser analisados com acuidade, de modo a tornar possível verificar os conflitos de interpretação sobre a realidade que exercem influência sobre o que propõem. Como foi possível perceber nas notícias sobre homofobia, a própria dificuldade conceitual do termo é fundamental para entender o posicionamento de determinados agentes. A considerar, ainda em referência a narrativas sobre acontecimentos ligados à homofobia, que suas origens são difusas, misturando componentes religiosos, jurídicos, culturais e uma gama de outras variáveis que complexificam sua compreensão e combate;

f) a construção teórica sobre os agentes jornalísticos requer acionar a perspectiva das disputas de sentido em jogo, dinâmica que tende ao infinito, e, portanto, sempre acionando novos agentes interessados em matizar os acontecimentos narrados;

g) as dimensões éticas não devem ser abandonadas nas proposições teóricas sobre os agentes jornalísticos, sob pena de se perder um componente fundamental para a verificação dos interesses em jogo e dos modos como jornalisticamente são construídas as narrativas;

h) embora a maior parte das análises tome como materialidade as narrativas jornalísticas, é fundamental considerar que, como proposto por Paul Ricoeur (1994), a leitura não é um momento de simples apreensão dos sentidos ofertados pela narrativa, mas de reconfiguração do mundo narrativo e de sua inserção nos mundos cotidianos. Com isso, coloca-se em xeque a visão simples e linear de que os conteúdos jornalísticos exercem influência unilateral sobre os leitores.

Essas proposições têm, claro, um caráter inicial, carecendo de ser melhor desenvolvidas e confrontadas com diferentes fenômenos e em diferentes perspectivas. No entanto, parece claro que a manutenção do termo "fonte" promove uma simplificação do 
processo noticioso que, com frequência, não apenas dificulta compreender as variáveis nele presentes, como, pior ainda, oferece obstáculos quase intransponíveis a um entendimento mais rigoroso e problematizador. As recorrentes correções do termo, assim como a construção de novas e atualizadas taxonomias nele baseadas, são indicadores claros de esforços de superar os inconvenientes gerados exatamente por seu uso. Se, como metáfora, "fonte" é algo morto, faz-se necessário construir outro operador que alcance a vivacidade e a diversidade do fenômeno jornalístico. Com isso, tanto o fenômeno quanto os próprios processos jornalísticos surgem como mais complexos, reticulares e abertos.

\section{Referências}

BENETTI, Márcia; FONSECA, Virgínia (Org). Jornalismo e acontecimento: mapeamentos críticos. Florianópolis: Insular, 2010.

BERGER, Christa et al. (Org.). Jornalismo e acontecimento: diante da morte. Florianópolis: Insular, 2013.

BORILLO, Daniel. Homofobia. Barcelona: Belaterra, 2001.

BORRAT, Héctor. Los periódicos, narradores en interación. In: BORRAT, Héctor e FONTCUBERTA, Mar de. Periódicos: sistemas complejos, narradores en interación. Buenos Aires: La Crujía, 2006.

BRAGA, Adriana et al. 0 chão de fábrica da notícia. Revista Intercom, São Paulo, v.37, n.1, p. 111-132, jan./jun. 2014.

BURNS, Lynette. Understanding Journalism. Nova York: Sage,2013.

CALCUTT, Andrew; HAMMOND, Philip. Journalism studies: a critical introduction. Londres: Routledge, 2011.

CÂMARA tem projetos que vetam adoção por casais de mesmo sexo. Folha de S. Paulo, São Paulo, 28 de abril de 2010, p. C1. Cotidiano.

CORNU, Daniel. Jornalismo e verdade: para uma ética da informação. Lisboa: Instituto Piaget, 1994.

CRATO, Nuno. Comunicação social - a imprensa: iniciação ao jornalismo. Lisboa: Editoria Presença, 1992.

ECO, Umberto. Lector in Fabula. São Paulo: Perspectiva, 2002.

ERIBON, Didier. Reflexões sobre a questão gay. Rio de Janeiro: Companhia de Freud, 2008. 
FACCHINI, Regina. Sopa de letrinhas? Movimento homossexual e produção de identidades coletivas nos anos 90. Rio de Janeiro: Garamond, 2005.

FARRÉ, Marcela. El noticiero como mundo posible. Buenos Aires: La Crujia, 2006

FÍGARO, R. (org.) As mudanças no mundo do trabalho do jornalista. São Paulo: Atlas, 2013.

FONSECA, Jurandira. Quem fala no jornalismo? In: LEAL, Bruno Souza et al. (Org.). Para entender o jornalismo. Belo Horizonte: Autêntica, 2014, p.89-102.

FRANÇA, Vera; OLIVEIRA, Luciana (Org.). Acontecimento: reverberações. Belo Horizonte: Autêntica, 2012.

FREIRE, Flávio. ‘Essa molecada não viu a cara da Aids'. Rio de Janeiro: 0 Globo, 2010. (p. $10)$.

GITTLIN, Todd. Un cúmulo de crisis: circulación, ingresos, atención, autoridade y confianza. Cuadernos de información y comunicación, Madri, v. 18, p.11-23, 2013.

HALL, Stuart. Da diáspora. Belo Horizonte: Ed. UFMG, 2003

LAGE, Nilson. A reportagem: teoria e técnica de entrevista e pesquisa jornalística. Rio de Janeiro: Record, 2001.

LEAL, Bruno Souza; ANTUNES, Elton; VAZ, Paulo Bernardo (Org.). Para entender o jornalismo. Belo Horizonte: Autêntica, 2014

LEAL, Bruno Souza; CARVALHO, Carlos Alberto de. Jornalismo e homofobia no Brasil: mapeamentos e reflexões. São Paulo: Intermeios, 2012.

LEAL, Bruno Souza et al. (Org.) Jornalismo e acontecimento: percursos metodológicos. Florianópolis: Insular, 2011.

LEAL, Bruno Souza; JÁCOME, Phellipy. Mundos possíveis entre a ficção e a não-ficção: aproximações à realidade televisiva. Revista FAMECOS, Porto Alegre, v. 18, p. 856-876, 2011.

LEAL, Bruno Souza; JÁCOME, Phellipy. Outros agentes na comunidade interpretativa do jornalismo. Revista Rumores, São Paulo, n.14, v.7, p.45-61, jul./dez. 2013.

MALCOLM, Janet. 0 jornalista e o assassino. São Paulo: Cia. Das Letras, 2011.

MORETZSOHN, Sylvia . O segundo olho do repórter: o papel dos motoristas na produção da notícia. Em Questão, v. 18, p. 77-91, 2012.

MUDANÇA de sexo no SUS. Revista Veja, São Paulo, p. 40, mar. 2008. 
NÉVEU, Eric. J o r n a l i s m o sem jornalistas: uma ameaça real ou uma história de terror? Brazilian Journalism Research, v.6, n.10, p.29-57, 2010.

NEVEU, Érik. Sociologia do jornalismo. São Paulo: Edições Loyola, 2006.

PENA, Felipe. Teoria do Jornalismo. Campinas: Contexto, 2005.

REBELO, José. 0 discurso do jornal: o como e o porquê. Lisboa: Notícias Editorial, 2000.

RICOEUR, Paul. A metáfora viva. 2. ed. São Paulo: Edições Loyola, 2005.

RICOEUR, Paul. A metáfora e o problema central da hermenêutica. In: RICOEUR, Paul.

Escritos e conferências 2: hermenêutica. São Paulo: Edições Loyola, 2011.

RICOEUR, Paul. Tempo e narrativa. Campinas: Papirus, 1994. Tomo I.

RYAN, Marie-Laure. Narrative as virtual reality. Baltimore: The John Hopkins University Press, 2001.

SELIGMAN, Felipe. STJ garante direito de adoção casal gay. São Paulo: Folha de S. Paulo, 28 de abril de 2010, p. C1, Cotidiano.

SCHUDSON, Michael. The sociology of news. New York: W. W. Norton \& Company, 2003.

SHOEMAKER, Pamela; VOS, Tim. Teoria do gatekeeping. Porto Alegre: Penso, 2011.

SILVA, Gislene et al. (Org). Jornalismo e acontecimento: tramas conceituais. Florianópolis: Insular, 2014.

TOMÉ, Bruno; LOPES, Felisbela. Quem fala o quê nas notícias de saúde do Público em 2009: uma análise crítica. Estudos de Jornalismo e Mídia, Florianópolis, n. 9, v. 2, p.362-339, jul./dez. 2012.

ZELIZER, Barbie (Org). The changing faces of journalism. New York: Routledge, 2008.

ZELIZER, Barbie. Taking journalism seriously. New York: Routledge, 2004. 


\title{
From sources to the journalistic agents: criticism for a dead metaphor
}

\begin{abstract}
"Source" is a term fairly frequent in journalistic processes and academic studies, and usually little problematized. Most of the time, it is a matter of a classification effort or it appears in approaches we could label as "under suspicion regarding its real purposes." Nevertheless, news sources seem to have life only in its immediate and mechanical relation to the universe of news production. Few academic works, however, note that the term is a very crystallized metaphor and might have lost their heuristic potential apprehension of journalistic phenomenon. In this sense, this article, starting from a large corpus of narratives about homophobia and HIV / AIDS in printed and electronic media, discusses the limits of usual notion of journalistic sources, observing them as journalistic agents.
\end{abstract}

\section{Keywords}

Sources. Agents. Journalism. Homophobia. Narrative.

Recebido em 15/09/2015

Aceito em 26/11/2015 